Article

\title{
Er,Cr:YSGG Laser-Activation Enhances Antimicrobial and Antibiofilm Action of Low Concentrations of Sodium Hypochlorite in Root Canals
}

\author{
Pablo Betancourt ${ }^{1,2}$, Josep María Sierra ${ }^{1}$ (), Octavi Camps-Font ${ }^{3}$, Josep Arnabat-Domínguez ${ }^{3}([)$ \\ and Miguel Viñas $1, *(\mathbb{D})$ \\ 1 Laboratory Molecular Microbiology \& Antimicrobials, Department of Pathology \& Experimental \\ Therapeutics, Faculty of Medicine, University of Barcelona, 08907 Barcelona, Spain; \\ pablo.betancourt@ufrontera.cl (P.B.); jmsierra@ub.edu (J.M.S.) \\ 2 Research Centre for Dental Sciences (CICO), Department of Integral Adult Dentistry, \\ Universidad de La Frontera, Temuco 4810296, Chile \\ 3 Department of Dentistry, Faculty of Medicine, University of Barcelona, 08193 Barcelona, Spain; \\ ocamps@ub.edu (O.C.-F.); joseparnabat@ub.edu (J.A.-D.) \\ * Correspondence: mvinyas@ub.edu; Tel.: +34-93-402-4265
}

Received: 11 November 2019; Accepted: 21 November 2019; Published: 22 November 2019

\begin{abstract}
The onset and persistence of endodontic infections due to residual biofilm after chemical disinfection promotes secondary bacterial infection. Alternative methods to disinfect operated root canals are a matter of great interest. The aim was to evaluate the antibacterial effectiveness of sodium hypochlorite $(\mathrm{NaOCl})$ at low concentrations activated by the Er,Cr:YSGG laser-activated irrigation (LAI) against 10-day-old intracanal Enterococcus faecalis biofilm. Biofilms were formed inside the root canals and divided into 7 groups (n13): $0.5 \% \mathrm{NaOCl}+\mathrm{Er}$,Cr:YSGG; Saline + Er,Cr:YSGG; 0.5\% $\mathrm{NaOCl}+$ syringe irrigation(SI); $2.5 \% \mathrm{NaOCl}+\mathrm{SI} ; 5 \% \mathrm{NaOCl}+\mathrm{SI} ;$ positive and negative controls. Bacterial survivors were counted and specimens visualized under scanning electron and confocal laser scanning microscopy. Treatments with $0.5 \% \mathrm{NaOCl}+\mathrm{Er}, \mathrm{Cr}$ :YSGG and $2.5 \% \mathrm{NaOCl}+\mathrm{SI}$ gave a significant reduction in the number of $\mathrm{CFU} / \mathrm{mm}^{2}$. Moreover, scanning electron microscopy and confocal laser scanning microscopy imaging confirmed and reinforced bacteriological data. Thus, Er,Cr:YSGG LAI proved to be able to improve the intracanal distribution of $0.5 \% \mathrm{NaOCl}$ after $60 \mathrm{~s}$ of activation, reaching the same level of effectiveness than $2.5 \% \mathrm{NaOCl}$. This is regarded as of clinical interest, since working with lower concentrations may contribute to reduce undesired effects.
\end{abstract}

Keywords: root canal infection; Enterococcus faecalis; biofilm; Er,Cr:YSGG laser

\section{Introduction}

The onset and persistence of endodontic infections due to residual biofilm after chemical disinfection promotes secondary bacterial infection [1]. Environmental conditions provided in the root canal favor polymicrobial growth. Nevertheless, Enterococcus faecalis is a frequently recovered bacterium from persistent infections [2]. E. faecalis is an aerotolerant anaerobic Gram-positive coccus, expressing several virulence factors, such as aggregation substances, enterococcal surface protein (Esp), pili (so called ebp (endocarditis and biofilm-associated pili)) and cytolysin [3]. Furthermore, its antimicrobial resistance seems to be strongly linked to its capacity to form biofilms [4]. A biofilm is defined as a growth mode of bacteria, bonded tenaciously to a substrate or to an interface or to each other, immersed in a self-produced extracellular polymeric substance (EPS). It has been pointed out that bacteria living in biofilms are phenotypically different from planktonic ones, at least in growth rates and gene transcription [5]. Theoretically, EPS offers protection against various environmental stresses, 
such as alkaline $\mathrm{pH}$, dryness, high concentrations of salts or lack of nutrients for long periods. Indeed, the bacterial removal from a biofilm is approximately 1000 times more difficult than in planktonic state [6]. The success of endodontic therapy lies, therefore, in the ability to eradicate bacterial biofilms. The complex and unpredictable nature of the anatomy of the root canal system, comprised of accessory canals, isthmi, side canals, and apical deltas, makes the complete removal of bacterial biofilms difficult. Therefore, adequate irrigation is crucial to disinfecting those areas that may not be cleaned sufficiently by instruments.

Conventional syringe irrigation (SI) is widely accepted. Yet it has been argued that in SI the irrigant may not reach the apical region of the canal [7] nor the dentinal tubules, subsequently allowing the persistence of biofilm and the survival of a significant number of viable bacteria, even when the apical preparation is considered to be "complete" [8].

Recently, laser-activated irrigation (LAI) has been proposed as an alternative method to achieve cleaning and disinfection of the root canal system being much more efficient than SI or passive ultrasonic irrigation (PUI) [9]. The LAI mechanism of action consists in the generation of cavitation bubbles through the high absorption of the laser energy by water. This is particularly relevant when using Erbium family lasers (Er:YAG: 2980 nm-Er,Cr:YSGG: 2780 nm) [10,11]. A turbulent flow and the subsequent formation of vapor bubbles in the liquid immediately after the Er,Cr:YSGG (2780 nm) laser activation has been demonstrated by Blanken et al. [12]. Bubbles expand during pulse and then implode generating pressure waves that first displace at supersonic speed (shock waves) and later at sonic speed (acoustic waves). This creates shearing forces along the root canal [13]. This offers a significant advantage over conventional SI, where significant effect take place only in the vicinity of the needle [7]. It has been demonstrated that LAI has bactericidal effect [14], improving the elimination of the dentin smear layer [15], and contributing to the elimination of residue from the apical third of the root [13].

Sodium hypochlorite $(\mathrm{NaOCl})$ is the most widely used endodontic irrigant; it has a broad antibacterial spectrum and dissolves dental pulp tissue [16]. It is used at concentrations ranging between $0.5 \%$ and $6 \%$ to varying degrees of effectiveness. It has been reported that cell damage is directly proportional to $\mathrm{NaOCl}$ concentration [17]. Moreover, prolonged contact causes damages to dentin and periodontal ligament cells, involving acute inflammatory reaction and pain [18]. In a previous work, we reported that Er,Cr:YSGG LAI of $0.5 \% \mathrm{NaOCl}$ increased the bactericidal effectiveness, on planktonic bacteria and young biofilms, in vitro, reaching the same level of antibacterial effectiveness as $5 \% \mathrm{NaOCl}$ [19]. This should make feasible the use of $\mathrm{NaOCl}$ at lower, and subsequently safer, concentrations. The study was conducted in a laboratory condition by using 24-h-old biofilms. Here we evaluate the antibacterial effectiveness of $0.5 \% \mathrm{NaOCl}$ activated by the Er,Cr:YSGG laser against a 10-day-old E. faecalis biofilm ex vivo, in extracted teeth. Effectiveness was estimated by both bacteriological and microscopy approaches

\section{Results}

\subsection{Bacterial Elimination}

Bacterial counts and interquartile range (IQR) values are shown in Figure 1. The Shapiro-Wilk test showed that the distribution was not normal $(p<0.05)$ and the non-parametric Kruskal-Wallis test confirmed significant differences between different groups $(p<0.05)$. The bactericidal index is shown in Table 1 and Figure 1 . In groups treated with $0.5 \% \mathrm{NaOCl}+\mathrm{LAI}$ and $2.5 \% \mathrm{NaOCl}+\mathrm{SI}$ there was a significant reduction in the number of CFU/ $\mathrm{mm}^{2}(p<0.001)$. Moreover, reduction of CFU was significantly greater for $5 \% \mathrm{NaOCl}+\mathrm{SI}$ group $(p<0.001)$. Lower efficiencies were achieved by saline solution $+{ }^{\prime} \mathrm{LAI}$ and $0.5 \% \mathrm{NaOCl}$ delivered by SI. Values were compared with the ones obtained in inoculated untreated teeth. 


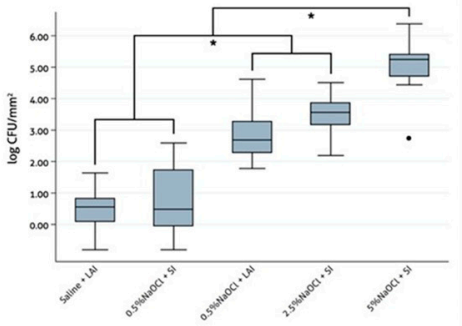

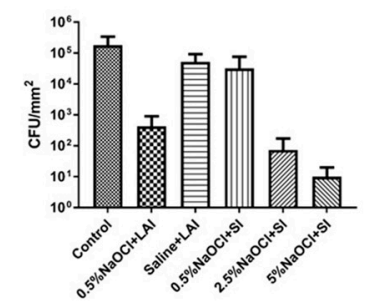

Figure 1. Bacterial counts values of surface area $\left(\mathrm{mm}^{2}\right)$ of E. faecalis biofilm after irrigation protocols. Data expressed as median and range. Control means untreated intracanal biofilm. (A): Box plot of bacterial reduction. (B): bacterial counts after resuspension of surviving microorganisms. * statistically significant difference $(\mathrm{P}<0.05)$

Table 1. Multiple independent variables on the bactericidal index. Statistically significant differences were set at $p<0.05$. LAI, laser-activated irrigation; SI, syringe irrigation.

\begin{tabular}{cccccc}
\hline Group & Treatment & $\mathbf{0 . 5} \% \mathbf{~ N a O C l}+$ LAI & Saline + LAI & $\mathbf{0 . 5} \% \mathbf{~ N a O C l}+\mathbf{S I}$ & $\mathbf{2 . 5 \%} \mathbf{~ N a O C l}+\mathbf{S I}$ \\
\hline 1 & $0.5 \% \mathrm{NaOCl}+\mathrm{LAI}$ & & & & \\
2 & Saline + LAI & $<0.001$ & & & \\
3 & $0.5 \% \mathrm{NaOCl}+\mathrm{SI}$ & $<0.001$ & 0.999 & & \\
4 & $2.5 \% \mathrm{NaOCl}+\mathrm{SI}$ & 0.3167 & $<0.001$ & $<0.001$ & $<0.001$ \\
5 & $5.0 \% \mathrm{NaOCl}+\mathrm{SI}$ & $<0.001$ & $<0.001$ & $<0.001$ & \\
\hline
\end{tabular}

\subsection{Scanning Electron Microscopy (SEM)}

Neither smear layers nor microorganisms were observed on the root canal walls in the negative control; the entrance to the dentin tubules appears open (Figure 2(A1,A2)). After bacterial incubation for 10 days, a heavy and dense biofilm of $E$. faecalis formed on the dentin surface, occluding the dentin tubules (Figure 2(B1,B2)) was seen. The specimens treated with the Er,Cr:YSGG laser and $0.5 \% \mathrm{NaOCl}$ showed an effective removal of both smear layer and biofilm. The root canal wall displayed open tubules and a clean surface (Figure 2(C1-C6)). In the saline + laser group (Figure 2(D1-D6)) and 0.5\% $\mathrm{NaOCl}+\mathrm{SI}$ group (Figure 2(E1-E6)), the E. faecalis biofilm and smear layer were observed on the surface of the root canal walls and inside the dentin tubules, showing that a complete biofilm removal was not achieved. None of the SEM micrographs showed signs of melting.
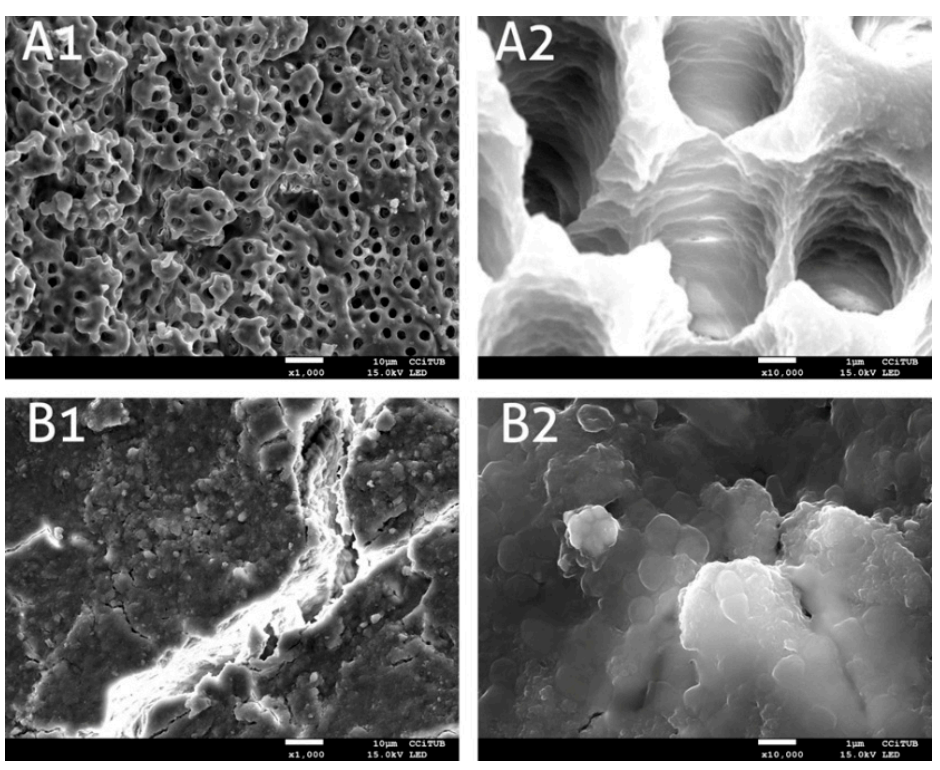

2-A

Figure 2. Cont. 


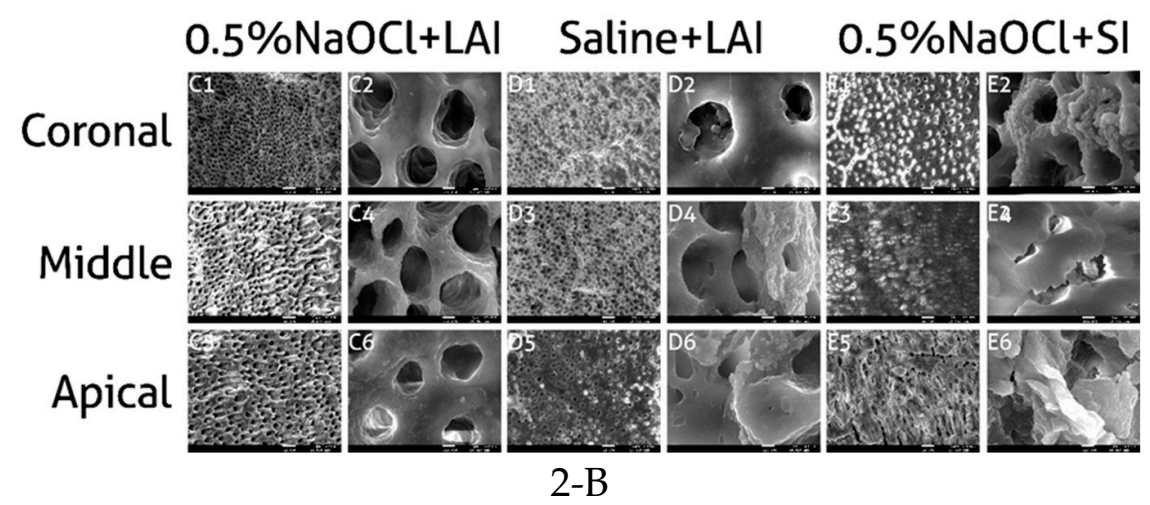

Figure 2. (A) SEM images of negative control group (non-inoculated root canals) (A1,A2) and positive control group (untreated 10 days old biofilm) (B1,B2). Magnification 1. $\times 1000 ; 2 . \times 10,000$. (B) SEM images of the coronal, middle and apical thirds of the root canal after different treatments. (C1-C6): Er,Cr:YSGG laser and $0.5 \% \mathrm{NaOCl}$ group. (D1-D6): saline + laser. (E1-E6): $0.5 \% \mathrm{NaOCl}+\mathrm{SI}$. Magnification 1, 3, 5: $\times 1000 ; 2,4,6: \times 10,000$.

\subsection{Confocal Laser Scaning Microscopy (CLSM)}

In the control group (Figure 3A) and saline + LAI group (Figure 3B), the CLSM images showed a dense biofilm of E. faecalis formed on the dentin surface, formed predominantly by alive bacteria (green). The images revealed the presence of both alive and dead bacteria in the passive irrigation group with $0.5 \% \mathrm{NaOCl}$ (Figure $3 \mathrm{C}$ ) with living cells predominating.
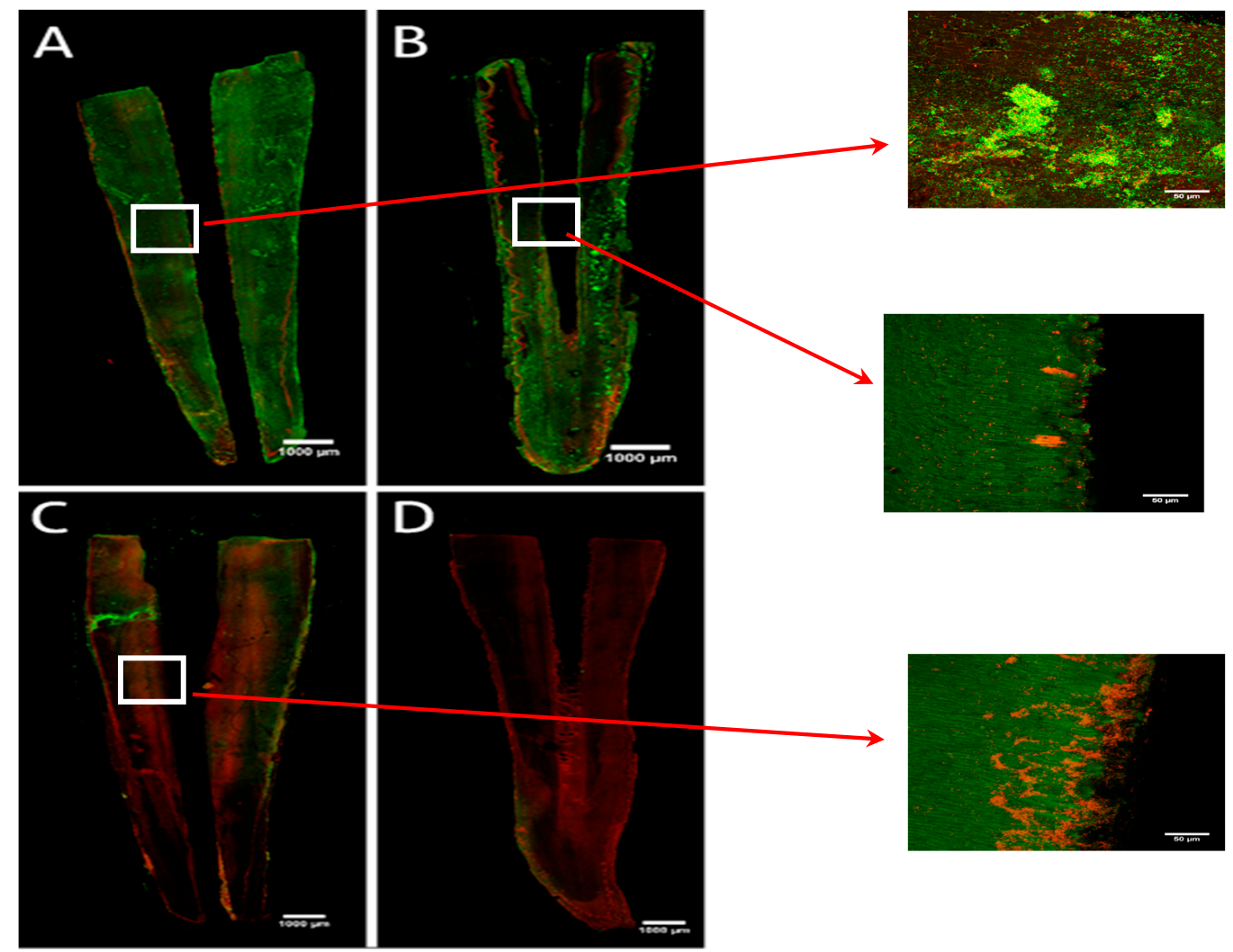

Figure 3. Representative CLMS images of E. faecalis biofilm on the surface of the root canal: (A) untreated biofilms, (B) Saline + Er,Cr:YSGG, LAI (C) $0.5 \% \mathrm{NaOCl}+$ LAI. (D) $5 \% \mathrm{NaOCl}+$ SI. Green: viable bacteria; Red: dead bacteria. Scale bar: $10 \mu \mathrm{m}$. 
Passive irrigation was not able to reach deep tooth areas. Finally, high bacterial mortality was seen after treatment with the $0.5 \% \mathrm{NaOCl}+\mathrm{LAI}$ group (Figure 3C) which was in agreement with the bacterial count results (Figure 1).

\section{Discussion}

The age of the biofilms used in experimental biology is frequently a matter of discussion. Most research is conducted with 24 or 48-h-old biofilms, while in clinics, it is highly likely that we have to fight much older biofilms (up to 10 days or more). Longer bacterial incubations afford more relevant characteristics thanks to the formation of mature biofilms. The time needed for colonization by E. faecalis and biofilm formation varies among the different studies; while some use $24 \mathrm{~h}$ of incubation [20], others use $48 \mathrm{~h}$ [21], or even much longer incubation periods. We used a 10-day biofilm [22,23] mimicking natural conditions. The bacterial colonization pattern on the dentin and inside the dentin tubules was verified by scanning electron microscopy.

There is no consensus regarding the actual time needed to completely eradicate E. faecalis biofilms. Radcliffe et al. [24] demonstrated that $0.5 \%$ and $1 \% \mathrm{NaOCl}$ concentrations need at least 20-30 min to fully remove E. faecalis planktonic cells, while $5.25 \% \mathrm{NaOCl}$ required only $2 \mathrm{~min}$ to achieve complete disinfection. In our case, $5 \% \mathrm{NaOCl}$ released with the SI protocol was significantly more effective at removing E. faecalis biofilm than the other treatments with or without activation $(p<0.001)$. The main negative fact is that $\mathrm{NaOCl}$ at such high concentrations is extremely irritating to the periapical tissue [18]. Thus, the need to find new alternatives that can make the most of the antimicrobial activity of $\mathrm{NaOCl}$ but at less toxic concentrations is a matter of great interest. Other strategies have been used for the same purposes, among them the use of predatory bacteria [25]. The different irrigation techniques have also been extensively studied [26].

It has been reported that laser-activated irrigation significantly enhances the effectiveness of root canal disinfection $[14,27]$. The expansive shockwaves contribute to the overall photomechanical effect by facilitating access of the irrigant to the apical third of the canals and the deepest areas of the dentin [9]. In addition, the increased movement of $\mathrm{NaOCl}$ inside the root canal system increases the contact between the active chlorine molecules and the organic matter and, therefore, improves the chemical effectiveness of the irrigant [28]. However, little is known of the antibacterial effectiveness of low concentrations of $\mathrm{NaOCl}$ because most LAI studies have focused on working with high concentrations of $\mathrm{NaOCl}[14,27,29]$. Working on human tooth root canals, we have demonstrated that $0.5 \% \mathrm{NaOCl}$ combined with the Er,Cr:YSGG laser can effectively disinfect them, being the use of a less toxic concentration of $\mathrm{NaOCl}$ feasible. The canals irrigated with LAI $0.5 \% \mathrm{NaOCl}$ showed a reduction of 3 logarithms in the CFU $/ \mathrm{mm}^{2}$ count. The SEM revealed a large part of the canal wall and tubules as being free of microorganisms. This finding is encouraging because its effect equaled that of $2.5 \%$ $\mathrm{NaOCl}$ administered by conventional irrigation. This is relevant as it demonstrates the existence of a synergic effect between the laser and low concentrations of $\mathrm{NaOCl}$. Similar results were obtained by Jaramillo et al. [30], who concluded that the activation of $0.5 \%$ sodium hypochlorite with an Er:YAG laser significantly increased its antimicrobial effectiveness. By contrast, Christo et al. [31] observed that, working on a biofilm model with extracted teeth, LAI had a limited potential to increase the antibacterial effect of $0.5 \% \mathrm{NaOCl}$. This may be due to the fact that the work was done using an low power Er,Cr:YSGG laser (0.5 W).

Teeth treated with conventional irrigation and $0.5 \% \mathrm{NaOCl}$ showed a minimum alteration of the E. faecalis biofilm since most of dentin tubules exhibited a high number of bacteria. The inability to achieve good results by $\mathrm{NaOCl}$ at low concentration without activation stands out the relevant interest of laser energy in the disinfection of the root canal at these low concentrations.

Despite obviously saline is not bactericidal, some bactericidal effects were observed when used as an irrigant with LAI. The related bacterial death may be due to the intense flow action created within the irrigant [31]. Although the combination of activation laser and saline produced an alteration of biofilm, E. faecalis remained within the dentin tubules and on the dentin surface. It should be noted 
that the combination of the laser and saline improved the elimination of the smear layer, supporting the observations made by Di Vito et al. [15].

It has been reported that $\mathrm{NaOCl}$ extrusion increases during activation by the laser. Peeters \& De Moore [32] demonstrated that the likelihood of extrusion is greater the closer the apex is placed to the optical fiber. Here we performed activation with the optical fiber in the coronal portion of the tooth for the duration of the activation, thereby decreasing the likelihood of irrigant extrusion. Recently, Peeters et al. [33] studied the degree of extrusion of radiopaque contrast medium in 20 teeth with open apex using Er,Cr:YSGG LAI ( $1 \mathrm{~W}, 35 \mathrm{~Hz})$. The results showed a total absence of contrast medium in every case, demonstrating the safety of the technique. Nevertheless, extreme caution should be exercised particularly in the vicinity of apical constriction to prevent extrusion.

It should be taken into account that laser has some disadvantages as is the price of equipment and may have some risks when non-expert dentists use inappropriate parameters. It has been seen that the increase in temperature caused by laser energy can produce undesirable effects in the dentin, such as cracks, small fissures or carbonization [34]. In our experiments, the laser fiber was used away from the dental apex and never made contact with the canal walls, thus protecting the structure from possible thermal damage. This was confirmed in the SEM analysis, where the undamaged dentin can be observed following treatment. In a 10-day-old E. faecalis biofilm in extracted teeth, the Er,Cr:YSGG LAI proved to be able to improve the antibacterial properties of $0.5 \% \mathrm{NaOCl}$ after $60 \mathrm{~s}$ of activation, reaching the same level of effectiveness as $2.5 \% \mathrm{NaOCl}$. This is of great clinical interest, because it demonstrates that a lower concentration of $\mathrm{NaOCl}$ may be useful diminishing undesired secondary effects.

\section{Materials and Methods}

\subsection{Specimens}

The study protocol was approved by the Clinical Research and Ethics Committee of the University of Barcelona (\#2016-23). A total ninety-one human single-rooted teeth extracted for therapeutics purposes were collected. To eliminate periodontal ligament remnants and calculus from the root surface, the specimens were subjected to cleaning using endodontic tips (ProUltra Zirconium Nitride, Dentsply Maillefer, Ballaigues, Switzerland) and a Gracey 7/8 curette (Hu-Friedy, Chicago, IL, USA). The specimens were stored in formalin solution $10 \%$ at $4{ }^{\circ} \mathrm{C}$ until use.

All teeth were decoronated under the cemento-enamel junction to a standardized length of $14 \mathrm{~mm}$ as described by Christo et al. [31]. A coronal reservoir of $5 \mathrm{~mm}$ was created with a \#016 cylindrical diamond bur (Komet, Rock Hill, SC) at the entrance of the root canal. Apical permeability and single canal confirmation were checked with a K-File \#10 (Dentsply Maillefer, Ballaigues, Switzerland). The working length (WL) was determined by reducing $1 \mathrm{~mm}$ from the point at which the K-File \#10 was visible through the apical foramen. The canals were instrumented using the conventional sequence of 0.02 taper files up to the master K-File \#45 (Dentsply Maillefer ${ }^{\circledR}$, Ballaigues, Switzerland). After the use of each instrument, the root canals were irrigated with $1 \mathrm{~mL}$ of $2.5 \% \mathrm{NaOCl}$ using a syringe and a 30-gauge side-vented needle (Becton Dickinson, Madrid, Spain) to the WL. The canals were irrigated with $1 \mathrm{~mL}$ ethylenediaminetetraacetic acid (EDTA) (Denta Flux, Madrid, Spain) for $1 \mathrm{~min}$, followed by $1 \mathrm{~mL}$ of $2.5 \% \mathrm{NaOCl}$ and $1 \mathrm{~mL}$ of saline. The apical foramen and the root surface were sealed with a double layer of nail polish (02 Nail Polish, Depend Cosmetic AB, Halmstad, Sweden) to prevent the extrusion of the irrigant through the apex and to provide a closed system [31]. The dental roots were stored in Eppendorf tubes and autoclaved at $121^{\circ} \mathrm{C}$ for $17 \mathrm{~min}$.

\subsection{Enterococcus Faecalis Biofilm Formation}

E. faecalis ATCC 29212 (American Type Culture Collection) was maintained by weekly subculturing on trypticase soy agar (TSA) plates (Scharlau, Sentmenat Barcelona, Spain). A single colony was inoculated in $40 \mathrm{~mL}$ of tryptic soy broth (TSB) medium and incubated at $37^{\circ} \mathrm{C}$. After $24 \mathrm{~h}$ of incubation, the culture was diluted 100 times in fresh TSB, and adjusted spectrophotometrically (Unicam UV-2 at 
$600 \mathrm{~nm}$ ) at OD600 $=1.3$ (i.e., $7.8 \times 108$ colony-forming units CFU/mL). Root surfaces were coated with $0.01 \%(w / v)$ poly-L-lysine hydrobromide (Sigma-Aldrich, Dorset, UK) to enhance bacterial adhesion and inoculated with $10 \mu \mathrm{l}$ of bacterial culture using a 30-gauge syringe and needle (Becton Dickinson, Madrid, Spain). The dental roots were placed in Eppendorf tubes and incubated at $37^{\circ} \mathrm{C}$ for 10 days. Re-inoculation at days 1, 4 and 7 were performed to ensure the presence of live bacteria during the incubation period [20]. Finally, the inner part of the root canal was gently washed with $1 \mathrm{~mL}$ of Ringer's $1 / 4$ solution to remove the free-floating microbes and liquids.

\subsection{Experimental Procedures}

The teeth were randomly distributed into seven groups $(n=13)$. Each group was submitted to a different treatment: (I) $0.5 \% \mathrm{NaOCl}+$ Er,Cr:YSGG LAI (II) Saline + Er,Cr:YSGG LAI (III) $0.5 \% \mathrm{NaOCl}+$ SI (IV) $2.5 \% \mathrm{NaOCl}+\mathrm{SI}$ (V) $5 \% \mathrm{NaOCl}+\mathrm{SI}$ (VI) Positive control (no treatment) (VII) Negative control (no bacteria). Eighteen teeth were then randomly divided in to two subgroups for investigation with CLSM $(n=8)$ and SEM microscopy $(n=10)$ techniques.

The SI protocol was done by slowly placing up to $5 \mathrm{~mL}$ of the irrigant into the WL and allowing it to act for $60 \mathrm{~s}$. Finally, canals were irrigated with $2 \mathrm{~mL}$ of sodium thiosulfate $5 \%$ to inactivate the remaining $\mathrm{NaOCl}$ and washed with $1 \mathrm{~mL}$ of saline.

Laser irradiation took place using an Er,Cr:YSGG pulsed laser (Waterlase iPlus; Biolase Technology, Irvine, CA, USA) at a wavelength of $2780 \mathrm{~nm}$. The laser operating parameters were $1 \mathrm{~W}$ of power, 10 $\mathrm{Hz}$ of repetition frequency, $100 \mathrm{~mJ}$ energy per pulse and $140-\mu$ s of pulse duration. The coaxial water spray from the Gold Handpiece (Biolase Technology, Irvine, CA, USA) was switched off throughout the treatment. An RFT 2 tip (200 $\mu \mathrm{m}$ in diameter, $21 \mathrm{~mm}$ long, calibration factor $>0.55$, Endolase, Biolase Technology, Inc. Irvine, CA) was used. It is a conical tip with a $50^{\circ}$ angle, designed for endodontic treatment. The real power was $0.55 \mathrm{~W}$ at $10 \mathrm{~Hz}, 55 \mathrm{~mJ}$ per pulse. Autoclaved tips were positioned only in the coronal reservoir during activation. During the laser irradiation cycles, irrigant was added as the coronal reservoir was empty; thus, LAI was permanently carried out in the presence of irrigant. The Er,Cr:YSGG laser was activated for $30 \mathrm{~s}$, followed by a rest phase of $30 \mathrm{~s}$ and ending with $30 \mathrm{~s}$ of activation ( $60 \mathrm{~s}$ of activation in total). Finally, sodium thiosulfate and saline were used as before.

\subsection{Bacterial Count}

Bacteria were suspended in Ringer $1 / 4$ by using an ultrasonic cleaner (Raypa, Barcelona, Spain) at maximum power followed by vortex agitation for $3 \mathrm{~min}$. Colony-forming units (CFU) per $\mathrm{ml}$ were enumerated by plating tenfold serial dilutions on TSA plates incubated for $24 \mathrm{~h}$ at $37^{\circ} \mathrm{C}$. Values were transformed to $\mathrm{CFU} / \mathrm{mm}^{2}$.

\subsection{Scanning Electron Microscopy (SEM)}

A water-cooled diamond cutting blade mounted on a precision cutting machine (Mecatome, Persi, France) was used to cut the specimens longitudinally. The two parts were mounted on the microscope supports by means of a conductive double-sided adhesive disc. Next, they were covered with a fine graphite layer to improve their electrical conductivity (Emitech K950X high vacuum evaporator) and examined in a Jeol J-7100F scanning electron microscope (Tokyo, Japan) at $15.0 \mathrm{kV}$. Visualizations were done at $1000 \times$ and $10,000 \times$ to assess the bacterial biofilm and the smear layer in the coronal $(10-12 \mathrm{~mm}$ from the apex), middle (6-7 $\mathrm{mm}$ from the apex) and apical (1-2 $\mathrm{mm}$ from the apex) parts.

\subsection{CLSM}

To stain the biofilms, a mixture of SYTO 9 and propidium iodide prepared at a dilution ratio of 1:2 $(1.5 \mu \mathrm{L}$ of SYTO 9 and $3 \mu \mathrm{L}$ of propidium iodide (PI) in $1 \mathrm{~mL}$ of Ringer $1 / 4)$ was applied to the whole biofilm. After $30 \mathrm{~min}$ of incubation in the dark at $37^{\circ} \mathrm{C}$, the stained biofilms were washed once with Ringer $1 / 4$ to remove nonspecific staining. Fluorescence was observed using a Zeiss LSM 880 spectral confocal laser scanning microscope (Carl Zeiss, Jena, Germany) equipped with a 488-nm 
argon laser and 561-nm diode lasers. The reconstruction of whole teeth was performed with stitched images of different focal planes obtained with 10x magnification objective ( 0.45 numerical aperture) using the Zen black software (Carl Zeiss, Jena, Germany). The zoom images were obtained with 40x immersion oil objective (1.3 numerical aperture). The image resolution was $1024 \times 1024$ pixels with both magnifications. ImageJ software (National Institutes of health, Bethesda, MD, USA) and IMARIS software (Bitplane AG, Zurich, Switzerland) were used to obtain LSM images.

\subsection{Statistical Analysis}

Statistical analysis was performed with Stata14 (StataCorp ${ }^{\circledR}$, College Station, TX, USA). Data were transformed logarithmically. The bactericidal effects were expressed as a bactericidal index (BI); i.e., the difference between the logarithm of the bacterial counts of the control and the treatment groups. The normality of the scale variables was explored using the Shapiro-Wilk test and the visual analysis of the P-P graph and the box plot. When normality was rejected, both the interquartile range (IQR) and the median were calculated. A statistical analysis was performed to compare the UFC/ $/ \mathrm{mm}^{2}$ values using the Kruskal-Wallis nonparametric test and Bonferroni's post hoc test for multiple comparisons. The level of significance was set at $p<0.05$.

Author Contributions: P.B. and J.M.S. performed the experimental section, did the observations, and participate in the discussions. O.C.-F. performed the statistics, J.A.-D. supervised the work in relation with the dentistry clinics challenges, and participate in the discussions. P.B. and M.V. conceived the research and wrote the paper

Funding: P.B. is recipient of a fellowship from Becas Chile from the Chilean Government (CONICYT)/No. 5594/2015. M.V. is a member of JPIAMR consortium. Laboratory supplies were partially financed through a fellow from Odontology section, University of Barcelona.

Conflicts of Interest: The authors declare no conflict of interest.

\section{References}

1. Ohsumi, T.; Takenaka, S.; Wakamatsu, R.; Sakaue, Y.; Narisawa, N.; Senpuku, H.; Ohshima, H.; Terao, Y.; Okiji, T. Residual structure of Streptococcus mutans biofilm following complete disinfection favors secondary bacterial adhesion and biofilm re-development. PLoS ONE 2015, 10, e0116647. [CrossRef] [PubMed]

2. Rosen, E.; Tsesis, I.; Elbahary, S.; Storzi, N.; Kolodkin-Gal, I. Eradication of Enterococcus faecalis biofilms on human dentin. Front. Microbiol. 2016, 7, 2055. [CrossRef] [PubMed]

3. Fisher, K.; Phillips, C. The ecology, epidemiology and virulence of Enterococcus. Microbiology 2009, 155, 1749-1757. [CrossRef] [PubMed]

4. Khalifa, L.; Shlezinger, M.; Beyth, S.; Houri-Haddad, Y.; Coppenhagen-Glazer, S.; Beyth, N.; Hazan, R. Phage therapy against Enterococcus faecalis in dental root canals. J. Oral Microbiol. 2016, 8, 1-11. [CrossRef] [PubMed]

5. Donlan, R.M.; Costerton, J.W. Biofilms: Survival mechanisms of clinically relevant microorgansims. Clin. Microbiol. Rev. 2002, 15, 167-193. [CrossRef] [PubMed]

6. Distel, J.W.; Hatton, J.F.; Gillespie, M.J. Biofilm formation in medicated root canals. J. Endod. 2002, 28, 689-693. [CrossRef]

7. Boutsioukis, C.; Lambrianidis, T.; Kastrinakis, E. Irrigant flow within a prepared root canal using various flow rates: A Computational Fluid Dynamics study. Int. Endod. J. 2009, 42, 144-155. [CrossRef]

8. Falk, K.W.; Sedgley, C.M. The influence of preparation size on the mechanical efficacy of root canal irrigation in vitro. J. Endod. 2005, 31, 742-745. [CrossRef]

9. Betancourt, P.; Merlos, A.; Sierra, J.M.; Arnabat-Dominguez, J.; Viñas, M. Er,Cr:YSGG Laser-Activated Irrigation and Passive Ultrasonic Irrigation: Comparison of Two Strategies for Root Canal Disinfection. Photobiomodul. Photomed. Laser Surg. 2019. [CrossRef]

10. Blanken, J.; Verdaasdonk, R. Cavitation as a working mechanism of the Er, Cr: YSGG laser in endodontics: A visualization study. J. Oral Laser Appl. 2007, 7, 97-106.

11. George, R.; Meyers, I.A.; Walsh, L.J. Laser Activation of Endodontic Irrigants with Improved Conical Laser Fiber Tips for Removing Smear Layer in the Apical Third of the Root Canal. J. Endod. 2008, 34, 1524-1527. [CrossRef] [PubMed] 
12. Blanken, J.; De Moor, R.J.G.; Meire, M.; Verdaasdonk, R. Laser induced explosive vapor and cavitation resulting in effective irrigation of the root canal. Part 1: A visualization study. Lasers Surg. Med. 2009, 41, 514-519. [CrossRef] [PubMed]

13. De Groot, S.D.; Verhaagen, B.; Versluis, M.; Wu, M.K.; Wesselink, P.R.; Van Der Sluis, L.W.M. Laser-activated irrigation within root canals: Cleaning efficacy and flow visualization. Int. Endod. J. 2009, 42, 1077-1083. [CrossRef] [PubMed]

14. Cheng, X.; Tian, T.; Tian, Y.; Xiang, D.; Qiu, J.; Liu, X.; Yu, Q. Erbium:Yttrium Aluminum Garnet Laser-Activated Sodium Hypochlorite Irrigation: A Promising Procedure for Minimally Invasive Endodontics. Photomed. Laser Surg. 2017, 35, 695-701. [CrossRef]

15. DiVito, E.; Peters, O.A.; Olivi, G. Effectiveness of the erbium: YAG laser and new design radial and stripped tips in removing the smear layer after root canal instrumentation. Lasers Med. Sci. 2012, 27, 273-280. [CrossRef]

16. Cullen, J.K.T.; Wealleans, J.A.; Kirkpatrick, T.C.; Yaccino, J.M. The effect of $8.25 \%$ sodium hypochlorite on dental pulp dissolution and dentin flexural strength and modulus. J. Endod. 2015, 41, 920-924. [CrossRef]

17. Zhang, W.; Torabinejad, M.; Li, Y. Evaluation of cytotoxicity of MTAD using the MTT- tetrazolium method. J. Endod. 2003, 29, 654-657. [CrossRef]

18. Zhu, W.C.; Gyamfi, J.; Niu, L.N.; Schieffel, G.J.; Liu, S.Y.; Santarcangelo, F.; Khan, S.; Tay, K.C.; Pashley, D.H.; Tay, F.R. Anatomy of sodium hypochlorite accidents involving facial ecchymosis-A review. J. Dent. 2013, 41, 935-948. [CrossRef]

19. Betancourt, P.; Merlos, A.; Sierra, J.M.; Camps-Font, O.; Arnabat-Dominguez, J.; Viñas, M. Effectiveness of low concentration of sodium hypochlorite activated by Er,Cr:YSGG laser against Enterococcus faecalis biofilm. Lasers Med. Sci. 2019, 34, 247-254. [CrossRef]

20. Licata, M.E.; Albanese, A.; Campisi, G.; Geraci, D.M.; Russo, R.; Gallina, G. Effectiveness of a new method of disinfecting the root canal, using Er, Cr:YSGG laser to kill Enterococcus faecalis in an infected tooth model. Lasers Med. Sci. 2015, 30, 707-712. [CrossRef]

21. Yavari, H.R.; Rahimi, S.; Shahi, S.; Lotfi, M.; Barhaghi, M.H.; Fatemi, A.; Abdolrahimi, M. Effect of Er, Cr: YSGG Laser Irradiation on Enterococcus faecalis in Infected Root Canals. Photomed. Laser Surg. 2010, 28, S91-S96. [CrossRef] [PubMed]

22. Bago Jurič, I.; Plečko, V.; Anić, I. Antimicrobial Efficacy of Er,Cr:YSGG Laser-Activated Irrigation Compared with Passive Ultrasonic Irrigation and RinsEndo ®Against Intracanal Enterococcus faecalis. Photomed. Laser Surg. 2014, 32, 600-605. [CrossRef] [PubMed]

23. Mohmmed, S.A.; Vianna, M.E.; Penny, M.R.; Hilton, S.T.; Mordan, N.; Knowles, J.C. Confocal laser scanning, scanning electron, and transmission electron microscopy investigation of Enterococcus faecalis biofilm degradation using passive and active sodium hypochlorite irrigation within a simulated root canal model. Microbiologyopen 2017, 6, 1-9. [CrossRef] [PubMed]

24. Radcliffe, C.E.; Potouridou, L.; Qureshi, R.; Habahbeh, N.; Qualtrough, A.; Worthington, H.; Drucker, D.B. Antimicrobial activity of varying concentrations of sodium hypochlorite on the endodontic microorganisms Actinomyces israelii, A. naeslundii, Candida albicans and Enterococcus faecalis. Int. Endod. J. 2004, 37, 438-446. [CrossRef]

25. Patini, R.; Cattani, P.; Marchetti, S.; Isola, G.; Quaranta, G.; Gallenzi, P. Evaluation of Predation Capability of Periodontopathogens Bacteria by Bdellovibrio Bacteriovorus HD100. An in Vitro Study. Materials 2019, 12, 2008. [CrossRef]

26. Eneide, C.; Castagnola, R.; Martini, C.; Grande, N.M.; Bugli, F.; Patini, R.; Cordaro, M.; Sanguinetti, M.; Olivi, G.; Isola, G.; et al. Antibiofilm Activity of Three Different Irrigation Techniques: An in Vitro Study. Antibiotics 2019, 8, 112. [CrossRef]

27. Cheng, X.; Xiang, D.; He, W.; Qiu, J.; Han, B.; Yu, Q.; Tian, Y. Bactericidal Effect of Er:YAG Laser-Activated Sodium Hypochlorite Irrigation Against Biofilms of Enterococcus faecalis Isolate from Canal of Root-Filled Teeth with Periapical Lesions. Photomed. Laser Surg. 2017, 35, 386-392. [CrossRef]

28. Macedo, R.G.; Wesselink, P.R.; Zaccheo, F.; Fanali, D.; Van Der Sluis, L.W.M. Reaction rate of $\mathrm{NaOCl}$ in contact with bovine dentine: Effect of activation, exposure time, concentration and pH. Int. Endod. J. 2010, 43, 1108-1115. [CrossRef] 
29. Souza, M.A.; Tumelero Dias, C.; Zandoná, J.; Paim Hoffmann, I.; Sanches Menchik, V.H.; Palhano, H.S.; Bertol, C.D.; Rossato-Grando, L.G.; Cecchin, D.; de Figueiredo, J.A.P. Antimicrobial activity of hypochlorite solutions and reciprocating instrumentation associated with photodynamic therapy on root canals infected with Enterococcus faecalis - An in vitro study. Photodiagn. Photodyn. 2018, 23, 347-352. [CrossRef]

30. Jaramillo, D.E.; Aguilar, E.; Arias, A.; Ordinola-Zapata, R.; Aprecio, R.M.; Ibarrola, J.L. Root canal disinfection comparing conventional irrigation vs photon-induced photoacoustic streaming (PIPS) using a buffered $0.5 \%$ sodium hypochlorite solution. Evid.-Based Endod. 2016. [CrossRef]

31. Christo, J.E.; Zilm, P.S.; Sullivan, T.; Cathro, P.R. Efficacy of low concentrations of sodium hypochlorite and low-powered Er,Cr: YSGG laser activated irrigation against an Enterococcus faecalis biofilm. Int. Endod. J. 2016, 49, 279-286. [CrossRef] [PubMed]

32. Peeters, H.H.; De Moor, R.J.G. Measurement of pressure changes during laser-activated irrigant by an erbium, chromium: Yttrium, scandium, gallium, garnet laser. Lasers Med. Sci. 2015, 30, 1449-1455. [CrossRef] [PubMed]

33. Peeters, H.H.; Suardita, K.; Mooduto, L.; Gutknecht, N. Extrusion of irrigant in open apex teeth with periapical lesions following laser-activated irrigation and passive ultrasonic irrigation. Iran. Endod. J. 2018, 13, 169-175.

34. Yamada, M.K.; Uo, M.; Ohkawa, S.; Akasaka, T.; Watari, F. Three-dimensional topographic scanning electron microscope and Raman spectroscopic analyses of the irradiation effect on teeth by Nd:YAG, Er:YAG, and CO2 lasers. J. Biomed. Mater. Res.- Part B Appl. Biomater. 2004, 71, 7-15. [CrossRef] [PubMed]

(C) 2019 by the authors. Licensee MDPI, Basel, Switzerland. This article is an open access article distributed under the terms and conditions of the Creative Commons Attribution (CC BY) license (http://creativecommons.org/licenses/by/4.0/). 